\title{
The Orange Book
}

\author{
Laurie L. Hill
}

Escalating drug prices are at the centre of the raging debates on the seemingly uncontrollable costs of providing healthcare. Making available generic substitutes for the more expensive, patented drugs is a core element of many healthcare cost-reduction plans. In the United States, the Orange Book serves to promote expedited entry of generic drugs into the marketplace while simultaneously protecting the interest of drug patent owners.

The Orange Book provides a public and detailed listing of drugs and drug products approved for use and sale in the United States by the US Food and Drug Administration (US FDA). Formally known as Approved Drug Products with Therapeutic Equivalence Evaluations, its original embodiment was as an orange-covered printed publication. Although it is now available exclusively online, the moniker 'the Orange Book' remains.

\section{What you can find in the Orange Book}

The Orange Book lists several categories of drugs: approved prescription drug products with therapeutic equivalence evaluations; approved over-the-counter (OTC) drug products for those drugs that may not be marketed without a New Drug Application (NDA) or an Abbreviated New Drug Application (ANDA) because they are not covered under existing OTC monographs; drug products approved under the Orphan Drug Act; and a cumulative list of approved products that have never been marketed or have other limited uses. The listing is updated monthly. Drugs approved only on the basis of safety tests or pre-1938 drugs are not included in the listing.

The Orange Book makes available a considerable amount of information on the listed drugs, including the active ingredient, proprietary name, drug applicant name and drug applicant number. Also provided is a series of uniform terms and codes defined within the Orange Book that indicate the various parameters evaluated for the listed drugs. Such parameters include pharmaceutical equivalents, pharmaceutical alternatives, bioavailability, bio-equivalent drug products and therapeutic equivalents.

Patent information for the listed drug products is also included in the Orange Book. The NDA review process requires the identification of any patents held by the applicant that claim the drug or a method of using the drug that could reasonably serve as a basis for patent infringement if a person engaged in the manufacture, use or sale of the drug without the appropriate patent license. Once the NDA is approved, the patent(s) identified by the NDA applicant is listed in the Orange Book, as well as its expiration date and current exclusivity data. The FDA publishes this information provided without review and will also add patents issued subsequent to the NDA approval.

\section{Role in the generic drug industry}

The patent information listed in the Orange Book serves the holder of approved drug patents as well as the generic drug maker. In the United States, a new drug can be legally sold only after the FDA determines that the drug is both safe and effective. The manufacturer of a new drug seeks approval from the FDA through the submission of a NDA. The NDA presents clinical data on safety and efficacy from studies carried out by the applicant. If the drug is patented, a generic drug company cannot perform those tests or enter the market without infringing the patents, and therefore either has to challenge the patent by making or using the drug or wait until the patent has expired. Waiting until the patent expires provides a de facto extension to the patent term because of the time required to conduct the necessary clinical trials. In an effort to streamline this process and expedite generic drug entry to the market, the Hatch-Waxman Act of 1984 revised the requirements for generic drug makers. Under this act, the generic drug maker can rely on the safety and efficacy clinical data submitted by the NDA applicant. The generic drug maker submits an ANDA that seeks to establish that the active ingredient in the previously approved drug product is the same as the active ingredient in the product made by the generic drug maker and that the generic product is bio-equivalent to the previously approved product. By eliminating the costs of expensive clinical trials, the federal government hopes to allow generic drug products to be ready for the marketplace at the time of patent expiration or to have sufficient economic incentive to challenge patents that might be invalid or which do not necessarily cover the generic drug product.

However, in exchange for avoiding the same expensive clinical testing required for an NDA, the ANDA applicant also must make certain certifications regarding the patents listed in the Orange Book as protecting the previously approved drug (BOX). If the ANDA application included a 'paragraph IV' certification of invalidity or non-infringement, the certification itself constitutes an act of patent infringement under the Hatch-Waxman Act. The patentee then has 45 days to file a patent-infringement suit. If the patentee files such a suit, the FDA cannot approve the ANDA until 30 months have passed, unless the case is decided before then or the court otherwise modifies the 30 -month period. These certifications and the resulting 30-month stay on generic drugproduct approval is an attempt to balance the desire for timely entry of the generic drug product into the market against the patent holder's rights and its investment for the approved drug product by allowing the patent holder to fully defend the relevant patent rights while allowing the generic drug maker to work towards preparing a drug product for market.

Laurie L. Hill, Ph.D. is a Patent Attorney at Morrison \& Foerster LLP, 3811 Valley Centre Drive, Suite 500, San Diego, California 92130, USA. e-mail:LHill@mofo.com

doi:10.1038/nrd1804

\section{REQUIRED ANDA CERTIFICATIONS}

The ANDA applicant must certify for a proposed generic drug as to each patent that claims the approved drug either: no patent information has been filed with the FDA (that is, no patents are listed in the Orange Book); the patent has expired; the patent will expire on a particular date; or the patent is invalid or will not be infringed by the manufacture, use or sale of the generic drug.

The ANDA applicant is required to provide notice to the patentee and the holder of the approved NDA that it has submitted such certifications. If the certification is that the patent is invalid or not infringed, the ANDA applicant must include a detailed statement of the legal and factual basis for its opinion of invalidity or noninfringement. 